\title{
MODELING OF ELECTRONIC STUDENT HEALTH RECORD FOR MONITORING STUDENT'S HEALTH BY COMMUNITY HEALTH CENTER, SCHOOL AND PARENTS IN INDONESIA
}

\author{
Retnowati* and Kemal N. Siregar \\ Faculty of Public Health, Universitas Indonesia
}

\begin{abstract}
Schools regularly collect student health data. School health is organized to improve the ability of students to live healthy so that students can learn, grow, and develop in harmony and become quality human resources. In Indonesia, school health priorities are included in the 3rd National MediumTerm Development Plan strategy. However, in Indonesia students, health data is underutilized because data documentation on paper causing some difficulties in terms of storage, use for monitoring and further analysis. The participation and involvement of parents, schools and community health centers in monitoring the health status of students today is still very limited due to the lack of information that can be accessed easily. Objectives: To design a student health record application model that can display student health examination results and connect the data to community health centers, schools and parents in real time. Method: Designing student health record application model with the context diagram, Entity Relationship Diagram (ERD), Table Relational Diagram (TRD), and user interface input and output. Results: The results of this study are a comprehensive student health record system model. The student health record will be applied in the form of mobile devices used by students and parents, which are connected to schools and community health centers by web-based platform. Conclusions: The student health record application model shows a systematic solution that is user friendly, immediately captures data, displays the dashboard in real time, directly connects to parents, schools and community health centers. All of this in the future if implemented properly can early detect student health problems and monitor the health status of students.
\end{abstract}

Keywords: Student health record, real-time data, web-based application, dashboard, monitoring student's health

\section{Introduction}

School health is organized to improve the ability of students to live healthy so that students can learn, grow, and develop in harmony and become quality human resources (Ministry of Health, 2020). In Indonesia, school health priorities are included in the National MediumTerm Development Plan strategy, namely organizing health services school age, including the school health unit (SHU) (Ministry of Health, 2020).

Schools regularly collect student health data. However, in Indonesia this data is underutilized because data documentation on paper causing some difficulties in terms of storage, use for monitoring and further analysis. Currently, health records (through health screening activities) of students that are carried out routinely at school are limited to notes on paper in the form of student health report cards which cause difficulties in further documentation and analysis (Fuad, 2018). Whereas the results of health screening are used to monitor the nutritional status of students, to screen healthy and unhealthy children, and to be used for mapping the health of learners, assessing the health development of school children, as well as being used as a consideration in planning, monitoring and evaluating Health Business activities (Ministry of Health, 2018).

School-age children are strategic targets for the implementation of health programs, in addition to being large ( \pm $24 \%$ ) of the population, they are also an easy target to reach because they are well organized in schools, which is 
localized with a clear structure and organization so that it is easy for health interventions to be carried out. Health problems in students are very complex and varied. Nutrition problems for school-age children and teenagers today are anemia by $22 \%$, stunting/short by $30 \%$, thinness by $10 \%$, and fat by $8 \%$ (Directorate of Nutrition and MCH, 2015).

Currently, recording in the context of monitoring student health which is carried out routinely in schools is only limited to paper in the form of student health report books, which causes difficulties in documenting and analyzing data (Johari, 2008). This results in monitoring the health status of students not functioning optimally. This research will improve this situation through the design of the student health record application which will be managed by the School Health Unit (SHU) Program Responsible Officer at the community health centers.

The participation and involvement of parents, schools and community health centers in monitoring the health status of students today is still very limited due to the lack of information that can be accessed easily by the parties. Even though the role of parents, schools and community health centers greatly affects the health status of students (Arisdanni \& Buanasita, 2018). This research will improve this situation by designing mHealth for PJ UKS Program in Community health centers and PJ UKS teachers in schools, as well as Personal Health Record (PHR) for parents of students, all of which are part of the Student Health Record application.

It is expected that with the student health record application, this will be a vehicle for realizing the Golden Generation in 2045, a demographic bonus, where school-age children are the focus of current health development. Thus, the long-term goal is for Indonesian children to become quality human resources. The participation and involvement of parents, schools and community health centers in monitoring the health status of students is also very limited due to the lack of easily accessible information.

Through this study, it is expected to be able to guarantee the availability of quality and continuous data and information that is integrated and easily accessible so that it can increase the role of parents, schools and community health centers. If it is implemented properly can monitor and improve the student's health.

\section{Method}

The system development method that was used in this study was system design with a prototype approach, but this study only reached the modeling stage. To achieve the research objectives, the following strategies were carried out:

a. Design the application architecture using Context Diagram and Entity Relationship Diagram (ERD).

b. Design the system database by using Table Relational Diagram (TRD) are based on the relational model, an intuitive, straightforward way of representing data in tables.

c. Design the system interface include input (form design) and output (dashboard design) interface.

\section{Results}

\section{Application Architecture Design}

Context Diagram 


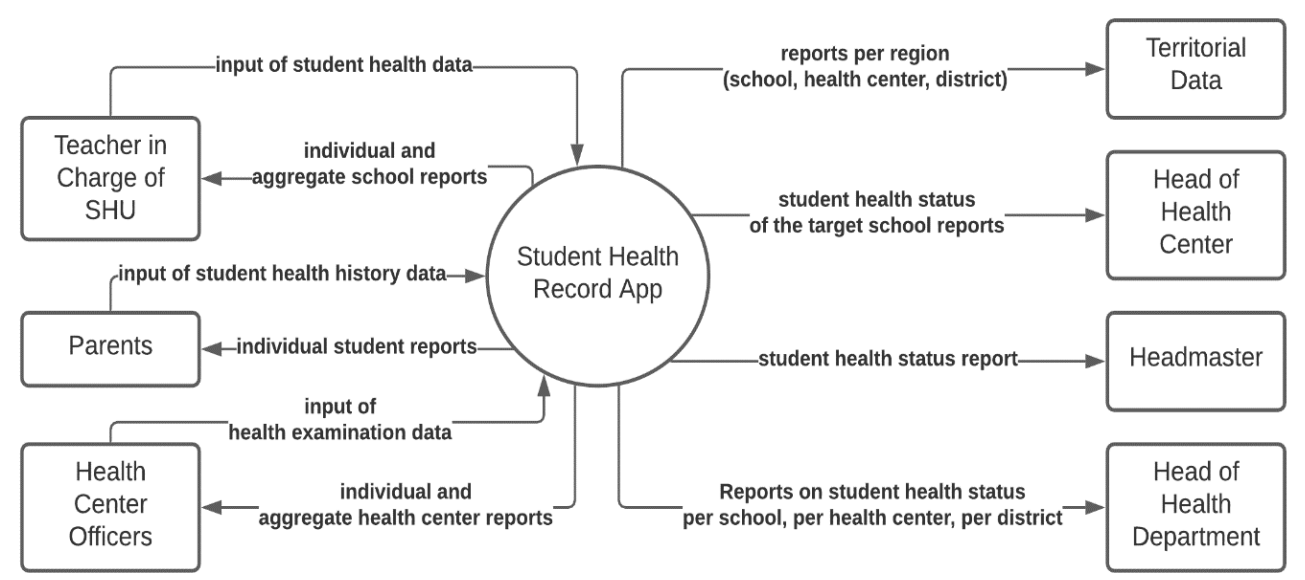

Figure 1. Context Diagram of Student Health Record

Figure 1. presents the application in the middle of the diagram and its relations with external entities, which are the inputs of data on the left side and the outputs on the right side.

The source entity who inputs data is an entity that provides data to the student health records, namely:

a. Parents: this entity provides data to the system in the form of student health history and family health history.

b. Teacher in charge in SHU: the entity provides data to the system in the form of student health data, including risk behavior/lifestyle assessments, mental and emotional health assessments, intelligence health assessments, reproductive health assessments and filling in the results of physical fitness examinations.

c. Health Centre Officers: entities provide data to the system in the form of data on students' physical health examinations, including examination of vital signs, examination of nutritional status, personal hygiene checks, vision health checks, hearing health checks, and dental and oral health checks.

The destination entity who is an entity output that receives data from the Student Health Record, namely:

a. Headmaster: the entity receives data from the information system in the form of student health examination results per class and school

b. Head of community health centers: the entity receives data from the information system in the form of student health checks per school and per work area

c. Head of Health District Office: the entity receives data from the information system in the form of student health check results per school, per district and district

d. Territorial data: this entity for the breakdown of areas by city and by community health centers 
Entity Relationship Diagram

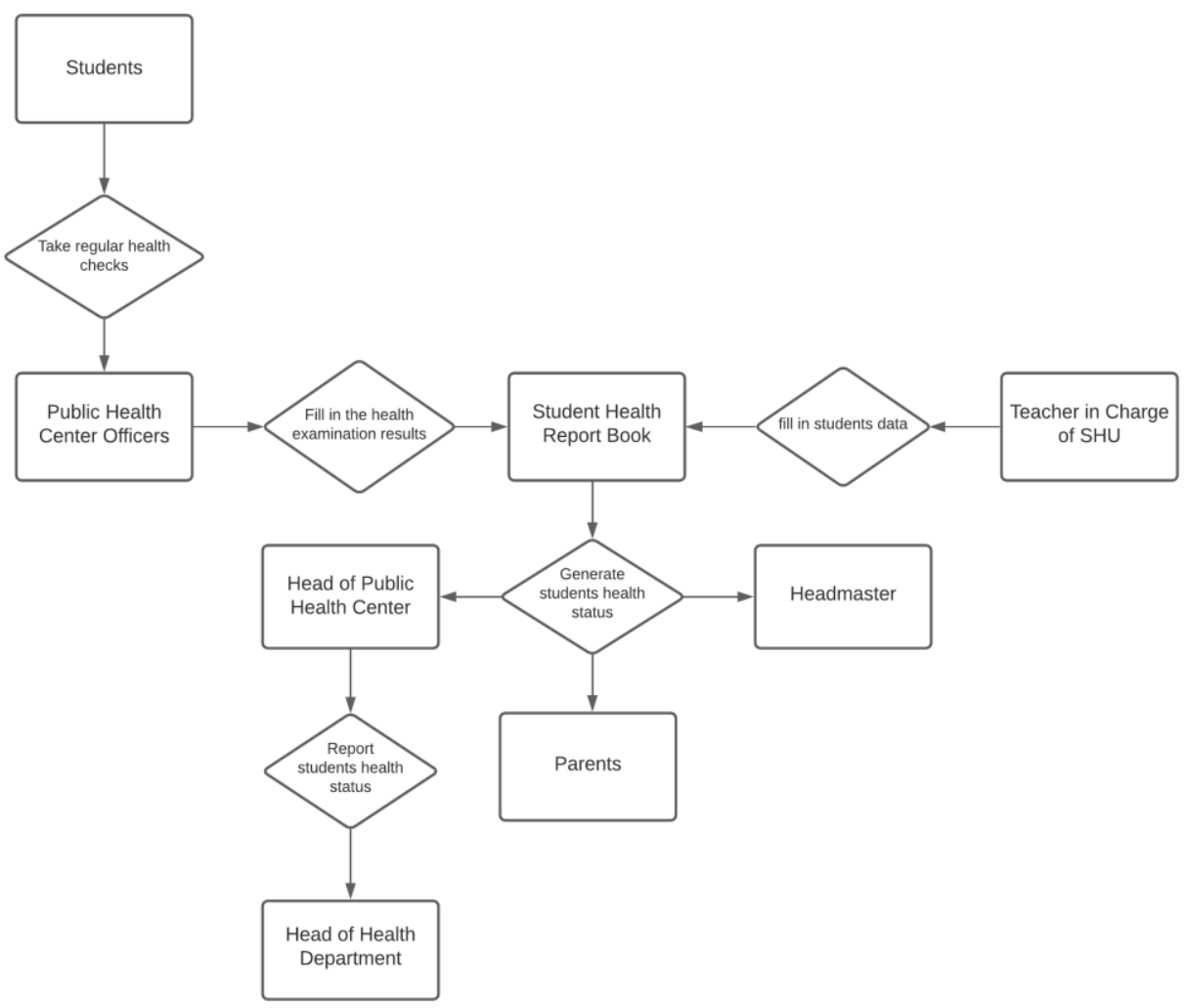

Figure 2. Entity Relationship Diagram

The diagram shows that data exchange can occur between entities which are useful for inputting student health examination results and sharing the data with parents and decision-holders. 


\section{Database Design}

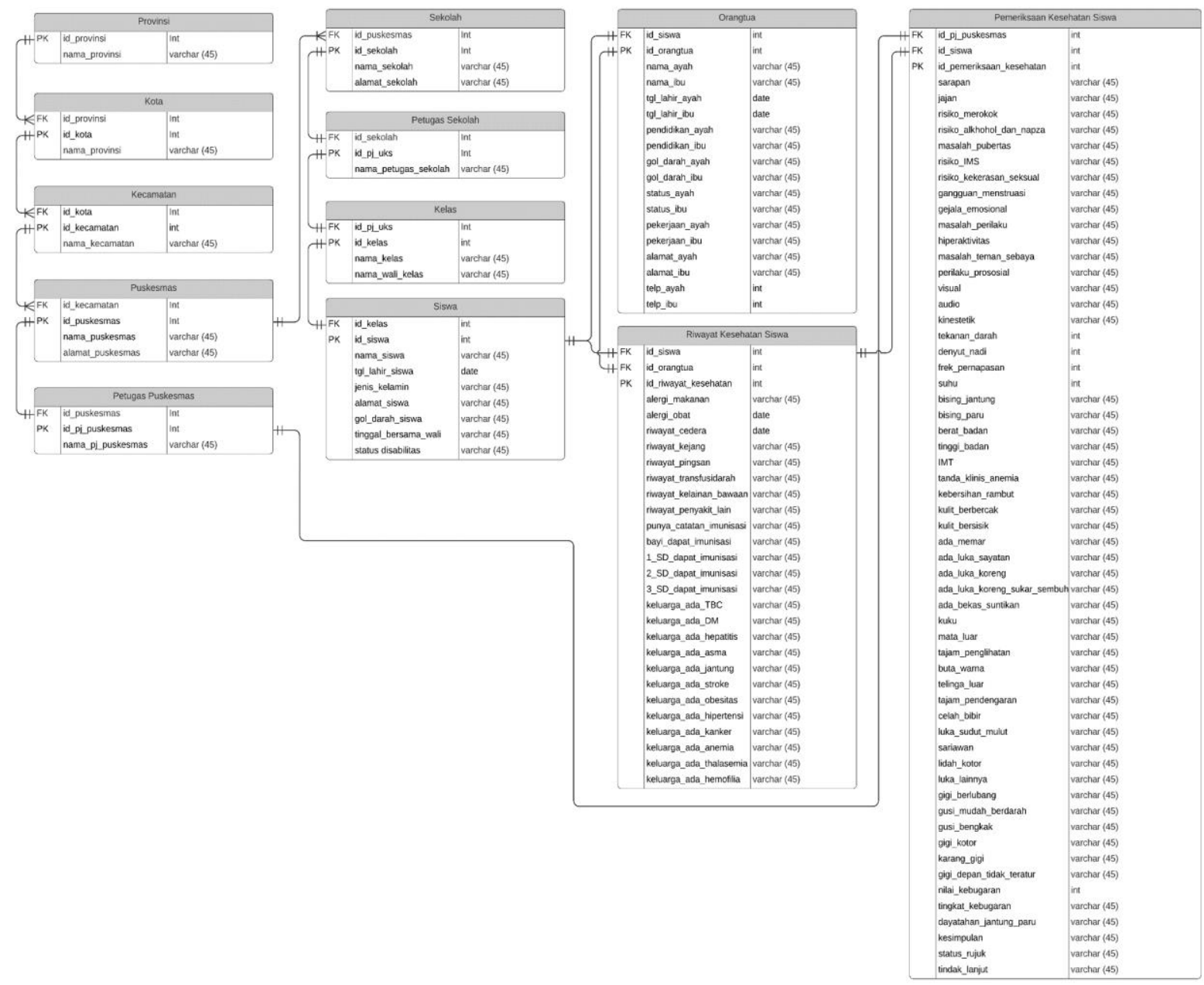

Figure 3. Table Relational Database

The diagram shows that the health center officers enter student health data, and parents enter the student's medical history, then the system generates health reports and health recommendations for parents and stakeholders.

\section{System Interface}

\section{Input Interface}

The login form is a form that must be accessed by every user to be able to use the application. The application will detect who the user is using and set the permissions of the user concerned. Through this form, users must enter a username and password. 

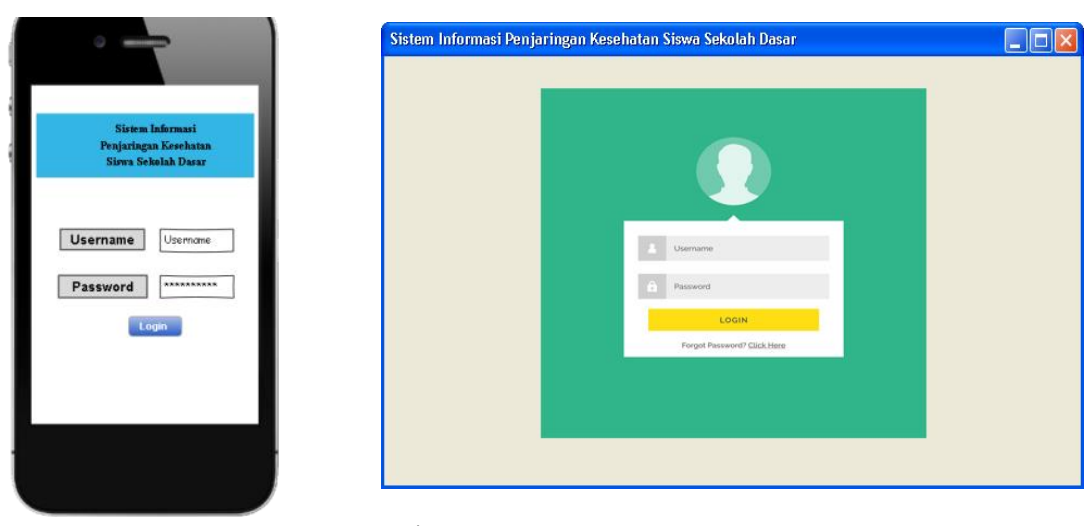

Figure 4. Login Form

The user interface is the main page after the user has logged in with access rights to the application. In this user interface, a user can receive information from users and provide information to users.

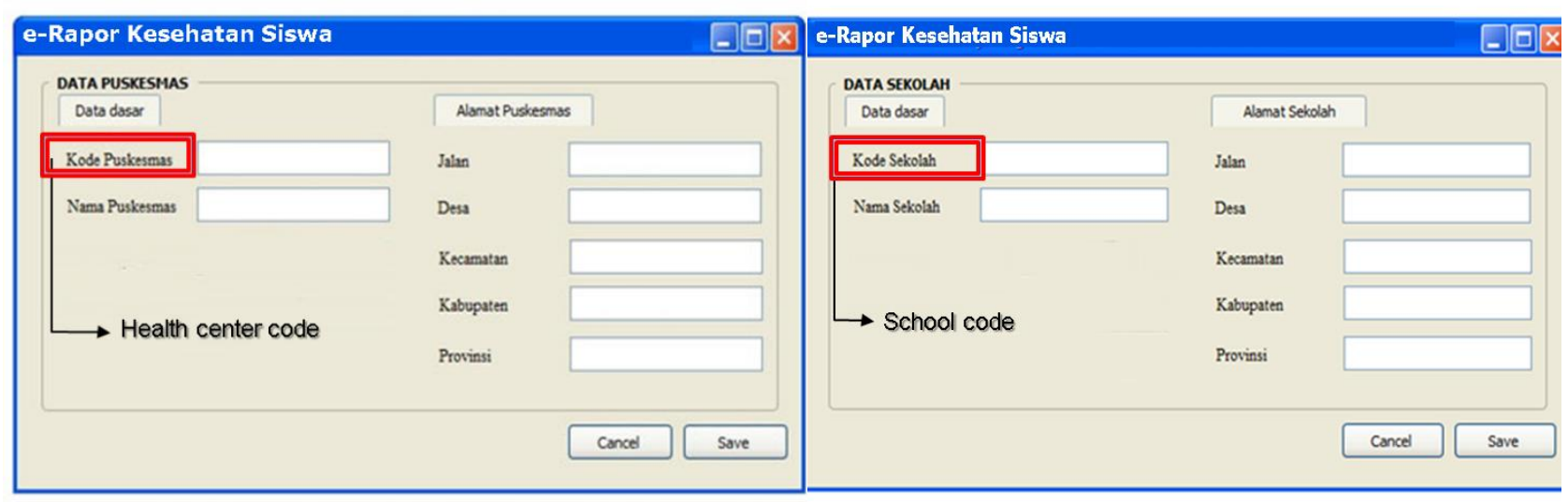

Figure 5. Health Center and Schools’ Data Entry

Figure 5 shows the filling of basic school data and community health centers data. The data will be automatically filled in when the community health centers code and school code are entered.

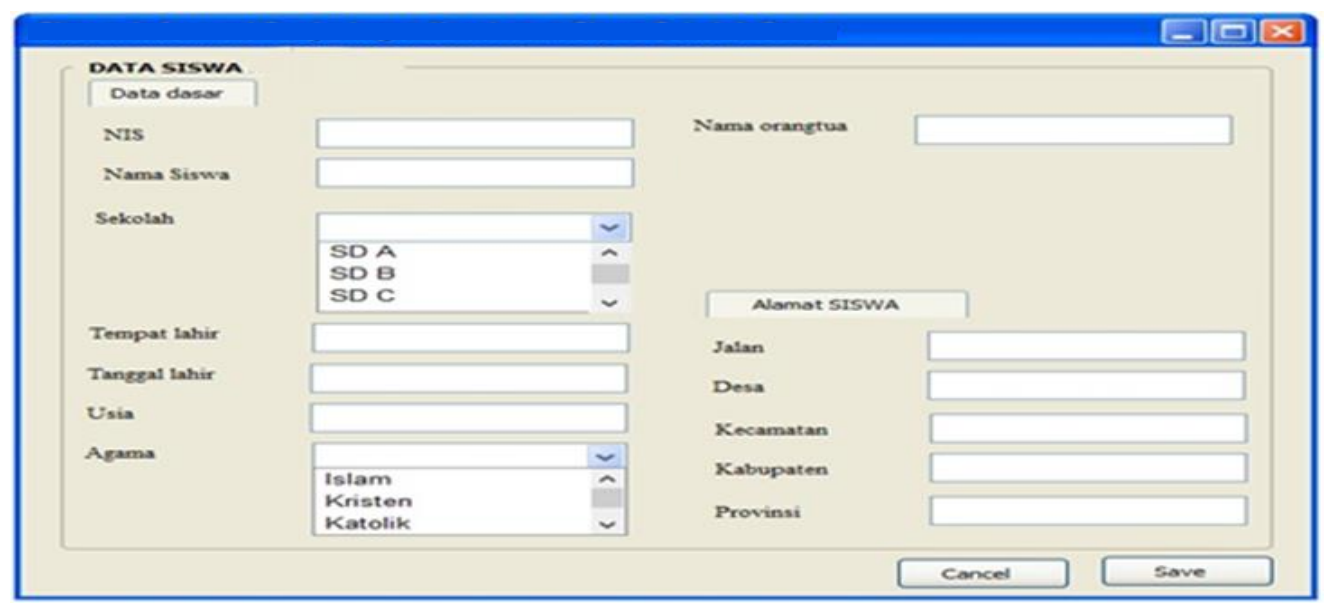

Figure 6. Student Data Entry 
Figure 6 shows the student's basic data entry. The name will be automatically filled in when the Student Identification Number (NIS) is entered.

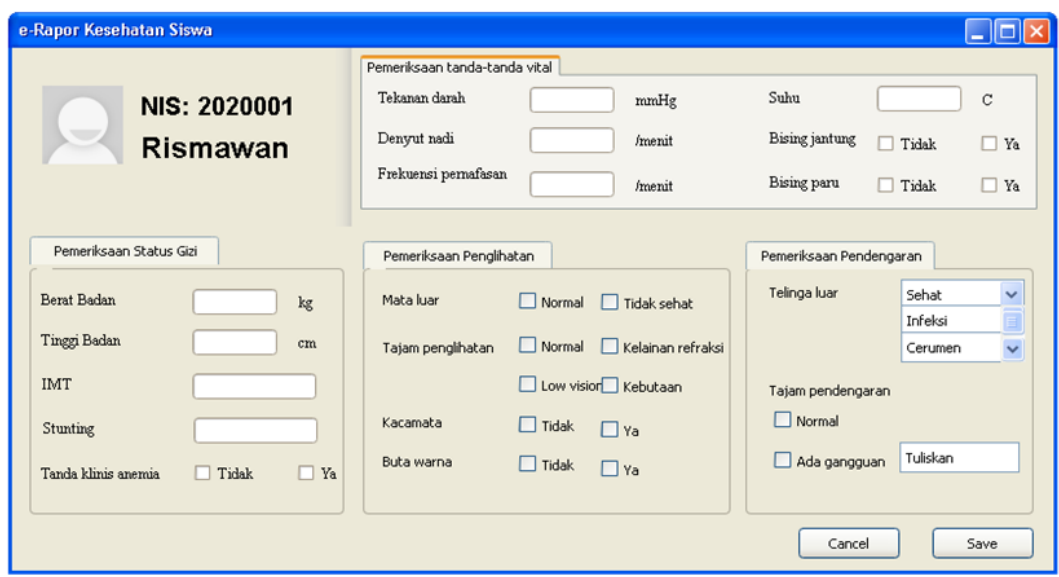

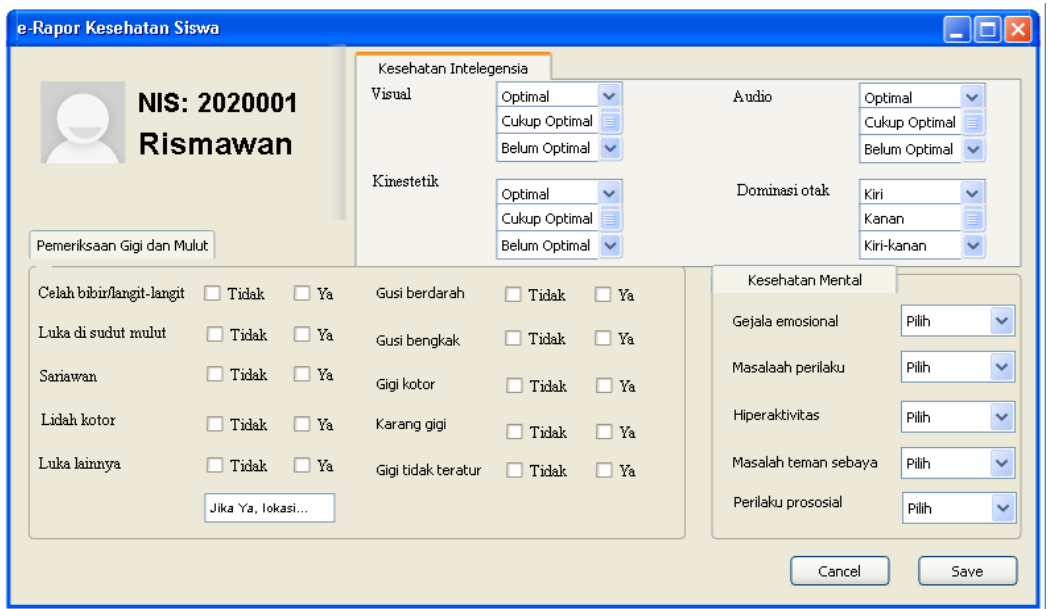

Figure 7. Health Asessment Form

Figure 7 shows the filling of the medical examination results per each student with a comprehensive medical examination. 
Output Interface (Dashboard Design)

a. Parents' Dashboard

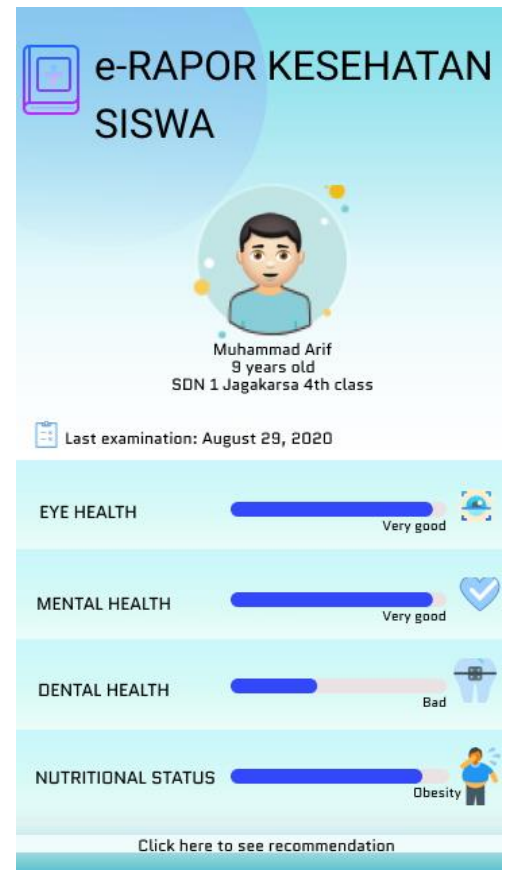

Figure 8. Parents' Dashboard

Figure 8 shows that for parents of students are the results of student health examination and health recommendations for their children.

b. School's and Community health centers Dashboard

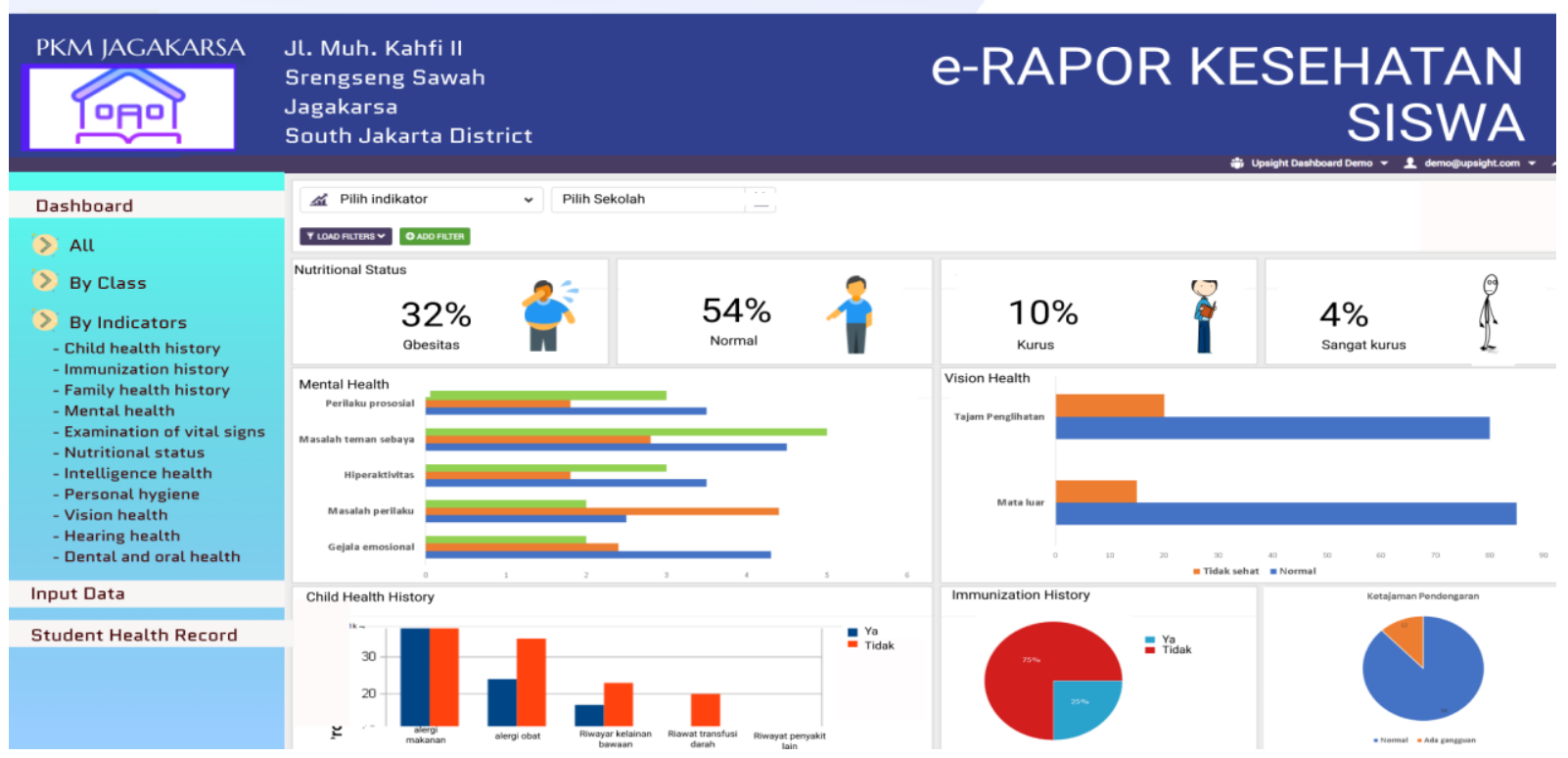

Figure 9. Schools and Community health centers' Dashboard 
Figure 9 is for community health centers and schools that will display the results of student health examination per indicator and per territorial

\section{Discussions}

1. The extent to which this study makes student health record design model efficient

In developing countries, health records in schools are currently manual, where the limitations of paper-based records include illegibility, ambiguity, incomplete data, poor availability and fragmentation of data (Muchangi and Nzuki, 2014). Furthermore, recording health information on paper hinders the continuity and quality of care for patients (Muchangi and Nzuki, 2014).

School health records are the functional parts of school systems which aim to carry out in practice the objectives of modern education. Hence record systems must be adequate for more careful examinations. There are still, however, many limitations to careful work by the school physician. Lack of sufficient health history, of necessary clinical data and often inadequate clinical facilities make for poor results of school medical work (Kleinschmidt, 1985).

This student health record model provides student health information, which will help schools and school health workers meet student needs. All of these School Health Service Programs are documented, in electronic formats.

System's model report presents the formulations of the health examination results, including school coverage and coverage of students receiving health examination, proportion of nutritional status, proportion of students with status examination results, as well as the proportion of students with cases of diseases.

2. The extent to which student health record design model has existed or been used or developed

Currently, Indonesia does not yet have Big Data on school student health which is managed by health centers. Student health records that are carried out routinely in schools are only limited to notes on paper in the form of student health report books, for elementary school, junior high school and high school students (Directorate of Nutrition and $\mathrm{MCH}, 2015)$.

Previously developed applications only developed one-way recording from community health centers without integrating the parents and schools (Masturoh et al, 2019). This design model is supported by integration parents and schools as seen in the context diagram.

3. The extent to which the student health record design model capable of producing quality data

Electronic health record must include A longitudinal collection of electronic health information for and about persons, immediate electronic access to person- and population-level information by authorized and only authorized, users Provision of knowledge and decision support that enhances the quality, safety, and efficiency of patient care, as well as Support of efficient processes for health care delivery (WHO \& PAHO, 2017).

The indicators used in the SHU program refer to a health screening or examination and the condition of the SHU (Ministry of Health, 2015). Based on the student health record model developed, the SHU health screening report presents the formulations of the SHU screening results, including school coverage and coverage of students receiving health screening, proportion of nutritional status, proportion of students with status, proportion of students with physical fitness tests, proportion of students with health screening. examination results, the proportion of students with cases of diseases. 
This study guarantee the availability of quality and continuous data and information that is easily accessible by developing an appropriate student health information system so that it can increase the role of parents, schools and community health centers, so if implemented properly can monitor and improve the health of students.

\section{Conclusions}

The student health record application model shows a systematic solution that is user-friendly, immediately capture data, displays the dashboard in real-time, directly connects to parents, schools and community health centers. All of this in the future if implemented properly can early detect student health problems and monitor the health status of students.

\section{Acknowledgment}

This research was conducted by assignment and funding from the Faculty of Public Health, Universitas Indonesia. A special thank goes to the Dean of the Faculty of Public Health, Universitas Indonesia and Directorate of Research and Development Universitas Indonesia.

\section{References}

Arisdanni, H., \& Buanasita, A. (2018). The Relationship between the Role of Friends, the Role of Parents, the Amount of Allowance and Perception of Snacks and the Incidence of Overnutrition in School Children (Study at SD Negeri Ploso 1/172, Tambaksari District, Surabaya in 2017). Amerta Nutrition; 2 (2), 189-196.

Directorate of Nutrition and MCH. (2015). Technical Guidelines for Health Screening and Periodic Examination in Primary and Secondary Education Units. Jakarta: Ministry of Health RI.

Fuad, Miftakhul. (2018). Database Development on a Web-Based Health Screening Information System in MAN 2 Bantul Yogyakarta.

Johari. (2008) Development and Application of School Health Business Information System (UKS) in Purwakarta Regency

Kleinschmidt, E. E. (1985). Purpose and Function of School Health Records. Journal of School Health; 5(9), 15 17. https://doi.org/10.1111/j.1746-1561.1935.tb09506.

Masturoh, Imas; Maulana Heri D; Suryani, Dewi Lena. (2019). Implementation Of School Children's Health Information System In The City Of Tasikmalaya In 2018.

Ministry of Health. (2020). The main points of the 2020-2024 Ministry of Health's Strategic Plan. Ministry of Health Strategic Plan Working Group 2020-2024.

Ministry of Health. (2018). Technical Instructions for Using Health Report Book

Ministry of Health. (2020). Guidelines for Public Health Program Indicators in the National MediumTerm Development and Strategic Planning 2020-2024.

Ministry of Health. (2015). Guidelines for Accelerated Development and Implementation of SHU. Child Health Development, MOH RI; 2015; 1-148.

Muchangi, D. and Nzuki, D. M.(2014). Determinants of Electronic Health in Developing Countries, International Journal of Arts and Commerce; 3(3), pp. 49-60.

World Health Organization, \& Pan American Health Organization. (2017). Handbook for Electronic Health Records Implementation. World Health Organization, June, 75; http://www.paho.org/ict4health/images/docs/DRAFT-Handbook_EHR_Implementation.pdf 